\title{
Editorial: A Canadian Journal with International Reach
}

I have had a special affinity with the Canadian Journal on Aging / La Revue canadienne du vieillissement (CJA/RCV) since my first-ever published paper appeared in the first-ever issue of the journal, over 30 years ago. I am not going to begin my editorial career at the $C J A / R C V$ with a self-citation, but you can look it up.

Assuming the role of editor-in-chief of the $C J A / R C V$ is an exciting and intimidating prospect. Excitement comes with an opportunity to support and continue the journal's proud tradition of outstanding scholarship in gerontology. An element of intimidation comes from my growing appreciation of the complexities and sensitivities of the role - from learning to navigate our online manuscript system to making judgments on the merits of scientific papers from a diverse range of methodological and disciplinary perspectives.

The CJA/RCV has had the good fortune to be served by outstanding editors-in-chief and editorial teams, and I am grateful for the opportunity to build on such a solid foundation. I am especially grateful for the support and guidance I have received from my immediate predecessor, Dr. Margaret Penning. I would also like to thank Carlene Brennan for her support through the transition process.

I note that since Dr. Penning gave her annual report at the 2014 annual meeting of the Canadian Association on Gerontology, we have had a complete turnover of the journal's editorial board. I would like to express my appreciation for the dedicated efforts of Dr. Penning and the other outgoing editors, including Dr. Michel Bédard, associate editor-in-chief; Dr. Laura Funk, book review editor; Dr. Nicole Caza, psychology; Dr. Maureen Markle-Reid, social policy and practice; Dr. Barbara Mitchell, social sciences; Dr. André Smith, social sciences; and Dr. Cara Tannenbaum, health and biological sciences. I look forward to working with the new members of the editorial team: Dr. Sylvie Belleville, associate editor-inchief; Dr. Kenneth Rockwood, book review editor; Dr. Martine Lagacé, psychology; Dr. Veronique Boscart, social policy and practice; Dr. Deborah van den Hoonard, social sciences; and Dr. George Heckman, health and biological sciences.

The $C J A / R C V$ is a Canadian journal with an international reach. In recent years, the journal has received manuscript submissions from more than 40 countries. $C J A / R C V$ is circulated to approximately 7,500 institutional subscribers; this number includes institutions from every continent. The journal is provided to nearly 5,000 institutions in the developing world as one of the journals offered by Cambridge University Press through the HINARI program of the World Health Organization. Despite these impressive statistics, I believe there is room for continued growth as an international journal.

I do not believe that a journal's "impact factor" is always a valid indicator of its importance. As the most important gerontology journal in Canada, and as one of the leading gerontology journals in the world, I believe the influence and importance of the $C J A / R C V$ is greater than its impact factor would suggest. That said, I would hope to see the impact factor of the $C J A / R C V$ show an upward trend in the coming years.

The $C J A / R C V$ provides an important venue for publication of an extremely diverse body of scholarly work, and this is clearly illustrated by the current issue.

The issue includes two review papers focused on health services and systems. A scoping review undertaken by Guruge, Thomson, and Seifi documents evidence of barriers and inequities older immigrants face in accessing mental health services, and identifies a number of priorities for related future research. Tourigny and colleagues report the results of a systematic review of systematic reviews on preventive home visits - this review was undertaken to advise the Ministère de la Santé et des Services sociaux du Québec (Québec's department of Health and Welfare) on the effectiveness of these home care programs. Despite an apparent wealth of available evidence - 10 previous systematic reviews were identified - the authors found insufficient evidence to draw firm conclusions either for or against these programs. The outstanding questions posed by the authors will sound familiar to those who have followed efforts to demonstrate the effectiveness of multidimensional geriatric services: What are the key program components? and, Who is most likely to benefit? A third question could also be posed: What are reasonable expectations for the outcomes of these programs?

In their paper, McGregor and her colleagues tackled a different subject but their work, too, portends significant health system implications; they analysed data collected using the RAI-MDS 2.0 assessment in Saskatchewan long-term care homes to investigate whether $24 / 7$ registered nurse coverage in long-term 
care homes is associated with higher quality of care, as measured by use of acute care services. Their findings suggest there may be such an association. Their caution in interpreting their findings is a reflection of the complexities and challenges of these types of analyses.

From a symbolic interactionist perspective, the paper by MacRae explores older women's perspectives of their interactions with their physicians, finding that the physician's personality and "bedside manner" were more important than technical skill or competence.

Two papers address aspects of assistive technologies and devices. There is growing interest in the potential of smart systems for in-home monitoring to reduce risk and improve independence for frail older persons, but the interest is accompanied by potential concerns about whether these systems will be well-received or perceived as an unwanted intrusion. These questions will be among the areas of research interest to be explored by the newly funded AGE-WELL Networks of Centres of Excellence (NCE) program (www.agewellnce.ca). In this issue, Lapierre and her colleagues report a mixed-methods study which found that caregivers would be willing to use a video-monitoring fall-detection system, but had some concerns about privacy and cost. Yip and colleagues report results of a literature review to generate recommendations for inclusive design of accessibility ramps.

Two papers are relevant to aging and cognitive function. Young-Bernier and colleagues explored the complex relationship between cholinergic activity and reaction time. They found that reduced cholinergic activity was not significantly associated with performance, and suggest that cholinergic dysfunction may need to be severe before there is noticeable impact on attention. Giroux and Stibre used a Delphi study to validate a tool to guide decision-making in competency assessment of older adults with cognitive impairment.

Additional papers reflect a variety of other gerontological concerns. Cusson and colleagues from Université de Sherbrooke, using data from the NuAge study, found that masticatory efficiency was not associated with intake of important nutrients.

Nicińska and Kalbarczyk-Stęclik report an ambitious and complex survival analysis to investigate the impact of past life events on risk of death, for Europeans aged 50 and older. Although their results indicate that past life events influence risk of death, some findings are surprising and warrant further research. For example, they found poor health in childhood to be correlated with a lower risk of death.

Driving and older adults will be the focus of a special issue in 2016; in this issue, the paper by Johnston, Borkenhagen, and Scialfa shows the importance of pursuing rigorous evaluation of methods to improve or assess driving skills in older persons.

Finally, two book reviews are also contained in this issue: Fernandez reviews the essays generated from the 2010 Encounters in Bad Aussee (Austria), which examined representations of aging in media, art, and literature, from a cultural studies perspective. Martin reviews Gawande's eloquent commentary on the inability of the medical care system to cope with aging and death.

I encourage you to continue to support the $C J A / R C V$ by contributing your best scholarly work, participating in the review process, and sharing any ideas you may have to improve the journal. And, also, by following on Twitter: @cjarcv.

Paul Stolee

Editor-in-Chief 